\title{
PENGISIAN AIRTANAH BUATAN (ARTIFICIAL RECHARGE) DALAM RANGKA MENGATASI BENCANA BANJIR LONGSOR DAN KETERSEDIAAN AIR TANAH DI KOTA PADANG
}

\author{
Helfia Edial \\ Jurusan Geografi FIS Universitas Negeri Padang \\ Idealhelfia.ef@gmail.com
}

\begin{abstract}
Problem of flooding and landslides in Indonesia are already an issue ordinary and natural, is due to geological conditions, geomorphological and meteorological Indonesia is very appropriate, ditambahlagi with the increasing number of population so many changes in land use of natural land into land settlements and land courts work. As a result, the problem of floods and landslides remain overshadow our lives. Several methods of flood and landslide risk reduction that can be done is to increase the capacity of infiltration of rainwater into the ground, therefore naturally infiltration process is reduced, then the artificial infiltration also can be done by methods as follows; Methods of spreading water on the surface "Water spreading", include; Methods basin. "Basin Method), Method trenches "Furrow method", Method of natural channel "Natural channel method", Method immersion "Flooding method", method of irrigation (irrigation method), method of replenishment of groundwater through pits, charging method of groundwater through wells injekasi, method "induced recharge". With this method, the risk of flooding and landslides will be reduced and even stopped with the help of other technical methods, in addition to the availability of the amount of groundwater can also be maintained.

Keywords; Flood, Infiltration and Groundwater
\end{abstract}

\section{PENDAHULUAN}

Masalah banjir dan longsor akhir-akhir ini makin banyak terjadi, baik didaerah pedesaan maupun perkotaan. Untuk perkotaan masalah banjir lebih sering terjadi akibat makin rapatnya lokasi bangunan, semakin sempitnya lahan peresapan dan makin meningkatnya jumlah kebutuhan penduduk terhadap airtanah. Sementara itu resiko longsor berpotensi pada wilayah pinggiran perkotaan dikarenakan dibatasi oleh kondisi alam perbukitan. Seperti kota Padang, lokasi longsor banyak terjadi disekitar perbatasan bagian selatan yaitu daerah Bungus Taluak Kabung dan pada pinggiran kota Bagian Timur yang dibatasi oleh Bukit Barisan yang pada bulan agustus dan september yang lalu terjadi peristiwa bencana banjir bandang dua kali berturut-turut.

Bencana banjir dan longsor ini sering terjadi pada saat-saat terjadinya musim hujan di wilayah Indonesia, sudah banyak usaha yang dilakukan oleh pemerintah daerah bersama rakyat untuk mangatasi permasalahan ini, namun 
bencana ini masih saja terulang setiap tahunnya. Selain usaha-usaha yang telah dilakukan oleh pemerintah tersebut, maka masih perlu dicarikan solusi tambahan agar peristiwa banjir dan longsor ini dapat diatasi.

Banyak wilayah di kota Padang ini yang masih selalu mengalami banjir disaat terjadi hujan lebat, diantaranya wilayah Aia Pacah, Balimbing, Siteba, Gunung Pangilun, Lubuh Buaya, Lolong dan sebagainya.

Secara Geologis daerah-daerah banjir tersebut kondisinya hampir sama, yaitu sama-sama berada pada daerah dataran aluvial dari hasil pengendapan sedimen beberapa aliran sungai yang ada, yaitu Bt. Arau, Bt. Kuranji dan Bt. Air Dingin dan berada di sepanjang pantai Kota Padang. Bahan penyusun batuannya pada umumnya terdiri dari Kerikil, Pasir dan Lempung, dengan geomorfologi kipas aluvial disekitar lereng kaki Bukit Barisan, dan kearah laut berselang seling antara Bukit Pasir dengan Bekas Rawa Belakang.

Pada umumnya banjir sering terjadi pada wilayah Rawa Belakang yang sudah banyak ditimbun dan dijadikan areal permukiman oleh penduduk serta daerah bukit pasir yang hampir tidak punya lahan resapan lagi. sehingga banjir pun dapat terjadi pada wilayah tersebut. Lahan kipas aluvial yang seharusnya dijadikan areal resapanpun sudah banyak berubah fungsi sebagai lahan bangunan akibat dari makin bertambuhnya jumlah penduduk.

\section{PEMBAHASAN}

Pengisian air tanah secara buatan (artificial recharge) dapat di artikan, suatu pekarjaan memperbasar jumlah volume air yang masuk ke dalam tanah atau batuan dengan mempergunakan beberapa metode (Jesus,M,E.,1980). Sedangkan Tood,D.K (1980) medefenisikan pengisian airtanah secara buatan, adalah suatu pekerjaan memperbasar jumlah peresapan air hujan atau tubuh air permukaan ke dalam formasi bawah pembukaan, dengan mempergunakan beberapa metode atau dengan mengubah kondisi alam secara buatan. Cara ini dapat mengurangi resiko banjir dan kekurangan airtanah.

Pengisian air tanah secara buatan merupakan salah satu cara yang efesien dalam penyimpanan, penambahan dan menjaga kelestarian serta keseimbangan air tanah di alam. Konsep pengisian air tanah ini dilakukan, apabila tubuh air 
permukaan yang digunakan dalam pengisian tidak dipergunakan untuk keperluan lain, misalnya sebagai pembangkit tenaga listrik untuk irigasi pertanian, untuk industri dan sebagainya.

Walton,W.C. (1970) menyatakan, bahwa pengisian air tanah secara buatan di maksudkan untuk menambah kuantitas air tanah, meningkatkan infiltrasi di lereng pegunungan dan perbukitan, mencegah terjadinya banjir, mengurangi dan mencegah intrusi airlaut kedaratan. Pada suatu daerah tertentu pengisian air tanah secara buatan tidak hanya mempunyai satu maksud atau tujuan, tetapi dapat juga mempunyai lebih dari satu, sebagai contoh pada daerah pantai di samping bertujuan untuk memperbesar jumlah cadangan air tanah, juga dimaksudkan untuk mengurangi dan mencegah intrusi air laut ke daratan.

Tood,D.K (1980) mengemukakan adanya beberapa metode atau cara pengisian air tanah secara buatan yang telah berkambang dan banyak dipergunakan di berbagai negara lain. Teknik pengisian tersebut antara lain:

a. Metode menyebarkan air di permukaan ("Water spreading"), meliputi:

- Metode cekungan. ("Basin Method”)

- Metode parit ("Furrow method")

- Metode saluran alam ("Natural channel method")

- Metode perendaman (“Flooding method")

- Metode irigasi (irrigation method)

b. Metode pengisian airtanah melalui lubang galian

c. Metode pengisian airtanah melalui sumur injekasi

d. Metode "induced recharge"

Ada beberapa faktor penting yang harus diperhatikan dalam penentuan dan pemilihan metode pengisianairtanah buatan secara buatan disuatu daerah, menurut Todd (1995) sebagai berikut:
a. Kondisi topografi
b. Kondisi geologi
c. Kondisi hidrologi
d. Jumlah air yang diperlukan untuk pengisian
e. Data iklim atau kondisi meteorologi 
f. Rencana penggunaan airtanah

g. Kulaitas air

h. Dan kondisi sosial budaya.

1. metoda penyebaran air dipermukaan (water spreading)

Adalah penyebaran airtanah diatas permukaan tanah, sehingga terjadi penambahan jumlah peresapan air permukaan kedalam tanah/batuan dan penambahan perkolasi dalam muka airtanah. Pada dasarnya metoda ini adalah sama dengan peresapan air hujan kedalam tanah yang berpengaruh langsung terhadap airtanah bebas pada akifer yg dangkal, serta sangat efektif untuk pengisian airtanah melalui retakan atau celah-celah.

Pada dasarnya metode ini adalah memberikan kesempatan kepada air untuk dapat meyerap kedalam tanah dengann cara menggenangkan diatas permukaan tempat berlangsungnya pengisian (recharge), dalam hal ini sangat dibantu oleh tekstur batuan/tanah tempat dilakukan penyerapan (Hendrayana, 1994)

2. Metode cekungan (basin method)

Air yang akan digunakan dalam pengisian dialirkan kedalam suatu cekungan yang dibuat dengan cara penggalian ataupun dengan cara pembuatan tanggul dan Dam kecil. Demensi cekungan bervariasi sesuai dengan kebutuhan atau perencanaan. Biasanya air yang digunakan adalah berasal dari pemonmpaan sumber air permukaan yang berada di dekat cekungan, dimana air tersebut diharapkan bebas lumpur dan pengotoran-pengotoran lain. Hal ini untuk menghindari tertutupnya dasar cekungan selama pengisian, yang dapat mengakibatkan terhalangnya peresapan air kedalam tanah.

3. Metode Parit (furrow method)

Metode ini dengan cara mendirtibusikan air permukaan pada suatu alur atau parit kecil yang relatif sejajar, dangkal, dan mempunyai dasar yang rata dan daerah yang tertutup, ini dilakukan agar mendapatkan kontak semaksimal mungkin antara permukaan iar dengan permukaan tanah, sehingga peresapan yang terjadi akan mencapai titk optimum

4. Metode saluran alam (natural chanel method) 
Metode pengisian airtanah ini adalah dengan cara memanfaatkan aliran sungai yang ada, dimana pada saluran sungai tersebut dibangun beberapa "check dam" berukuran relatif kecil secara melebar atau melintang memotong aliran, dengan adanya beberapa check dam yang memotong aliran tersebut, dimaksudkan untuk memperlambat jalannya aliran sungai dan memperpanjang waktu kontak antara air dan dasar sungai, sehingga akan memperbesar jumlah peresapan air sungai kedalam lapisan tanah/batuan dibawahnya

Metode ini hanya dapat dipergunakan pada sungi "influent" yaitu sungai yang mempunyai permukaan air yang lebih tinggi dari pada permukaan airtanah. Dengan demikian sungai tersebut akan mampu meresapkan dan menambah air kedalam akifer disekitarnya (Hendrayana 1994)

5. Metode perendaman (flooding method)

Methode ini akan sangat baik pada daerah yang bertopografi relatif datar dan luas, air permukaan yang disebarkan untuk tujuan pengisian airtanah secara buatan akan sangat besar kemungkinannya lebih optimal, dan pengaliran permukaan (run off) akan sangat kecil sehingga penyimpangan tujuan pengisian menjadi lebih kecil. Untuk menghindari aliran permukaan dibuat parit-parit. Air yang mengalir ke parit-parit di alirkan kembali pada saluran induk dan selanjutnya disebarkan kembali pada daerah resapan/perendaman. Dengan demikian akan didapatkan suatu penyebaran air yang merata.

Kelemahan methode ini antara lain adalah seringnya didapankan endapanendapan lumpur pada daerah perendaman, hal ini disebebkan oleh kecepatan aliran air yang relatif lambat.

\section{Metode Irigasi (Irrigation Method)}

Pada daerah irigasi seringkali air disebarkan diatas permukaan tanah yang mempunyai tujuan untuk memperbesar julah cadangan airtanah, disamping untuk keperluan irigasi daerah pertanian atau persawahan disekitarnya, yaitu dengan cara menyalurkan air secara sistematis pada tanah yang diolah melalui saluran, sehingga dapat menambah jumlah cadangan airtanah disekitar daerah irigasi. Metode ini banyak dipergunakan pada daerah pertanian ataupun daerah persawahan yang luas. 
Bebarapa metode yang telah diauraikan diatas dapat digunakan untuk pengisian airtanah yang semakin langka untuk daerah perkotaan, apalagi dalam rangka memperkecil masalah bencana banjir. Banjir adalah salah satu akibat dari makin kurangnya peresapan air hujan (infiltrasi) kedalam tanah. Hal ini dapat disebabakan karena makin sempitnya lahan-lahan resapan airhujan, makin banyaknya lahan-lahan yang ditutupi dengan bahan pengeras seperti semen, aspal dan makin luasnya lahan tutupan oleh bangunan karena kebutuhan pemukiman serta industri dan perkantoran.

Cara lain yang sangat baik untuk dilakukan masyarakat untuk memperkecil resiko banjir adalah dengan memperbanyak penanaman pohon disekitar perkarangan perumahan, cara ini dapat memperbesar pori-pori tanah sehingga proses peresapan air hujan akan menjadi lebih besar, sehingga airhujan yang turun tidak semuanya akan menjadi limpasan yang dapat berakibat terjadinya resiko banjir, disamping itu ketersediaan cadangan airtanah juga akan semakin terjamin.

\section{KESIMPULAN}

1. Untuk mengatasi resiko banjir akibat dari hujan diwilayah perkotaan adalah dengan cara melakukan peresapan airtanah buatan dengan berbagai metode yang sesuai.

2. Pengisian airtanah buatan akan dapat menjaga ketersediaan cadangan airtanah

3. Penanaman pohon disekitar perkarangan dapat memperbesar infiltrasi sehingga dapat memperkecil resiko banjir dan dapat meningkatkan jumlah cadangan airtanah

4. Dalam membangun perumahan sebaiknya tetap disediakan lahan terbuka untuk peresapan airtanah. 


\section{DAFTAR PUSTAKA}

Hendrayana Heru, 1994, Pengelolaan Airtanah "Kursus Singkat" Angkatan I Yogyakarta 6 - 15 Juli 1994, Fakultas Teknik Geologi UGM.

Jesus, M.E. 1980, The Case For Artificial Recharge, Drillers Journal, Vol 52, No.1. page $7-11$

Tood DK. 1995. Groundwater Hidrology, 3rd ed, john Willey and Sons Inc, New York.

Walton, W.C, 1970 Grounwater Resources Evaluation, Mc. Graw Hill Book Company Inc, New York. 